\title{
GENES, BOLEADEIRAS E ABISMOS COLOSSAIS: ELEMENTOS PARA UM DIÁLOGO ENTRE GENÉIICA E ANTROPOLOGIA
}

\section{Michael Kent}

\section{University of Manchester - Inglaterra}

\section{Ricardo Ventura Santos}

\section{Escola Nacional de Saúde Pública/Fundação Oswaldo Cruz - Brasil}

Em primeiro lugar, gostaríamos de agradecer à geneticista Maria Cátira Bortolini por seu interesse e envolvimento para com nosso artigo, bem como por ter preparado um instigante conjunto de comentários. Nossos agradecimentos também a Ruben Oliven e aos demais editores de Horizontes Antropológicos pela oportunidade de travar o presente diálogo. Como um dos principais objetivos de nosso texto é abordar assuntos e desenvolver reflexões que possam ser relevantes tanto para a comunidade genética quanto para a antropológica, estamos particularmente satisfeitos com o reconhecimento manifestado por Bortolini quanto a essa relevância. Sua réplica levanta diversas questões que buscaremos abordar nos parágrafos a seguir, ainda que de forma condensada, devido ao espaço disponível.

Um primeiro aspecto relaciona-se ao que interpretamos como um estreito alinhamento de Bortolini com um princípio básico dos estudos de ciência e tecnologia (Science and Technology Studies - STS) e da antropologia da ciência: que ciência e sociedade fazem parte de um único domínio. Em seu comentário, ela se refere a "fortes influências socioculturais" e "margens flexíveis para atividades interpretativas" na estruturação da pesquisa científica. Sua resposta também expressa interesse em compreender como tais envolvimentos se efetivam na prática. Potencialmente, tal perspectiva ajuda a estabelecer uma base conceitual comum a partir da qual um diálogo entre geneticistas e antropólogos pode ser construído, além de vir a se tornar relevante.

Um segundo elemento mencionado por Bortolini vincula-se à metodologia de pesquisa empregada por cientistas sociais no estudo da genética. Ela 
coloca ênfase na importância do método etnográfico na tentativa de compreensão do mundo cotidiano da pesquisa de laboratório e do conhecimento produzido pelos geneticistas. Isso sugere haver uma maior predisposição ao engajamento com a pesquisa antropológica quando esta está baseada na etnografia, a qual, em princípio, objetiva capturar a perspectiva êmica dos geneticistas. Os procedimentos etnográficos, obviamente, são centrais tanto para a antropologia quanto para os estudos na linha de STS. Ainda assim, é válido enfatizar que a crítica antropológica endereçada a pesquisas genéticas com populações humanas - por exemplo, no quadro envolvendo o Projeto Diversidade do Genoma Humano, nos anos 1990 - tem frequentemente sido formulada a partir de perspectivas dos antropólogos e das populações-alvo das pesquisas genéticas, sem necessariamente uma igual preocupação em compreender o ponto de vista dos geneticistas (ver, por exemplo, Brodwin, 2002; Cunningham, 1998; Marks, 2003; Tallbear, 2007). Sem querer entrar no mérito da relevância de tais críticas, a ausência de tal perspectiva pode ter contribuído para os "colossais abismos” mencionados por Bortolini, e ter impedido a procura por uma saída para as controvérsias.

Outro elemento levantado por Bortolini se refere às consequências sociais derivadas do conhecimento genético, um aspecto que abordamos em mais de um momento em nosso artigo. Na pesquisa biomédica em geral, incluindo aquelas na área da genética, há complexos aparatos regulatórios de ordem bioética, como é o caso da necessidade de aprovação dos protocolos de investigação nos comitês de ética. Tais rotinas fazem com que, sobretudo em fases anteriores à coleta dos dados, se produza a possibilidade de reflexões sobre as consequências em potencial das pesquisas. Como se tornou evidente durante as múltiplas conversas ao longo do trabalho de campo da pesquisa que resultou em nosso artigo - na própria UFRGS e em outros laboratórios no Brasil -, uma vez que o conhecimento gerado deixa o laboratório e começa a circular em outros domínios, os geneticistas tendem a colocar a responsabilidade por seus usos sociais e suas consequências em atores alhures ao campo científico. Vários comentários de Bortolini, inclusive o seu convite para se refletir sobre as consequências sociais de se relativizar a extinção dos Charrua, sugerem haver uma preocupação entre os geneticistas quanto às consequências que investigações podem vir a produzir. É desnecessário enfatizar que tal perspectiva transcende os critérios formais impostos pelos comitês de ética.

Horizontes Antropológicos, Porto Alegre, ano 18, n. 37, p. 379-384, jan./jun. 2012 
Além disso, segundo ela, os antropólogos poderiam fazer uma contribuição construtiva nesse domínio como parte de um contínuo diálogo.

A incorporação do conhecimento e das técnicas genéticas nas múltiplas dimensões da vida cotidiana resultou na emergência de padrões de relações sociais centradas nas formas de subjetividade que evocam repertórios biológicos, o que tem sido alternativamente caracterizado como "biossociabilidade" (Rabinow, 1996), “comunidades genéticas imaginadas” (Simpson, 2000) ou “cidadania genética” (Heath; Rapp; Taussig, 2004; Rose, 2006). Além disso, o conhecimento genético vem crescentemente desempenhando um papel proeminente na definição e na contestação de identidades sociais diferenciadas, assim como nas negociações de direitos políticos reivindicados em nome de tais identidades (Brodwin, 2002, 2005; Gaspar Neto; Santos; Kent, 2012; Kent, 2011; Parfitt; Egorova, 2005; Reardon, 2005; Tallbear, 2007). À medida que a genética se capilariza por domínios da vida social que têm sido tradicionalmente área de interesse para os antropólogos, torna-se fundamental tanto para estes quanto para os geneticistas alcançar uma compreensão mais aprofundada dos processos através dos quais essa incorporação se efetiva.

Em parte, os argumentos pelos direitos coletivos dos povos indígenas no Brasil e em outros países da América Latina são frequentemente baseados na ideia de reparação dos danos históricos que esses grupos sofreram, o que se manifesta na forma de perda demográfica e de território, além de redução da autodeterminação. Por vezes, argumentos genéticos são acionados nesses debates. Em nosso trabalho abordamos, em vários trechos, como as evidências genéticas têm sido utilizadas no caso dos Charrua. No Brasil, há diversos outros exemplos quanto à presença de argumentos genéticos em debates públicos, como é o caso da população negra. Na perspectiva de setores dos movimentos sociais, as evidências genéticas, ao apontar a elevada miscigenação da população brasileira, ajudam a minar reivindicações por reparação das populações negras contemporâneas pelos danos históricos causados pela escravidão, pois questionam a existência de continuidade biológica entre a população escravizada e os negros atuais (ver, por exemplo, Motta, 2007). Na visão de vários geneticistas, por sua vez, a questão da elevada miscigenação tem implicações que vão além de reconstruções da trajetória de formação histórica e biológica da população brasileira, alcançando áreas como o planejamento e a implementação de políticas públicas na área da saúde, entre outras (Suarez-Kurtz, 2009). 
Ao mesmo tempo que o presente diálogo exemplifica e se torna parte das micropolíticas da interpretação científica, chama atenção para novos elementos. Ao escrever que "a herança charrua vai além das boleadeiras", Bortolini não somente afirma a continuidade genética entre os Charrua e os gaúchos contemporâneos com um grau de certeza significativamente maior que nas suas publicações nas revistas científicas, como também sinaliza que se trata de uma questão de contínuo interesse, que inclusive está sendo investigada no âmbito de outro projeto de pesquisa em andamento (Candela). A perspectiva de novos cenários de investigação faz com que a "vida social” das investigações sobre as contribuições indígenas nos gaúchos contemporâneos continuamente se reatualize, não se limitando ao passado. Por envolver outros conjuntos de amostras e novos arsenais metodológicos, além de se inserir em contextos sociopolíticos emergentes, é certamente de interesse continuar a analisar, de um ponto de vista antropológico, as novas faces da "vida social" das investigações sobre a ancestralidade dos gaúchos.

Finalmente, é importante ressaltar o arranjo bastante singular do presente intercâmbio nas páginas de Horizontes Antropológicos. Enquanto tem se tornado relativamente comum a presença de comentários e réplicas nos periódicos de antropologia - tal qual na Current Anthropology -, isso normalmente envolve a participação de outros cientistas sociais trabalhando na mesma área temática. É incomum ver os próprios sujeitos da pesquisa etnográfica “respondendo" de forma direta aos que os investigaram. Em uma escala expressiva, aconteceram, em âmbito internacional e sobretudo na década de 1990, trocas entre antropólogos e cientistas, estes usualmente na posição de sujeitos de pesquisa. Muitos desses intercâmbios se efetivaram como parte das então denominadas "guerras da ciência” (Franklin, 1995). Uma diferença significativa com relação à presente situação é que as reações dos cientistas não aconteceram necessariamente mediante convite, de modo que as trocas se deram muito mais em um espírito de controvérsia que de diálogo. Parece-nos que Bortolini está se referindo a essas controvérsias ao empregar os termos "abismos colossais” e "preconceito” para caracterizar as relações entre genética e antropologia. A arquitetura de intercâmbio de ideias e perspectivas que os editores de Horizontes Antropológicos propiciaram nestas páginas pode ser um caminho produtivo em direção ao estabelecimento de uma antropologia mais simétrica. Isso não somente em relação aos geneticistas, como também, em termos gerais, aos sujeitos de pesquisa antropológica de uma forma mais ampla. 


\section{Referências}

BRODWIN, P. Genetics, identity, and the anthropology of essentialism. Anthropological Quarterly, v. 75, n. 2, p. 323-330, 2002.

BRODWIN, P. "Bioethics in action” and human population genetics research. Culture, Medicine and Psychiatry, v. 29, n. 2, p. 145-178, 2005.

CUNNINGHAM, H. Colonial encounters in postcolonial contexts: patenting indigenous DNA and the Human Genome Diversity Project. Critique of Anthropology, v. 18, n. 2, p. 205-233, 1998.

FRANKLIN, S. Science as culture, cultures of science. Annual Review of Anthropology, n. 24, p. 163-184, 1995.

GASPAR NETO, V. V.; SANTOS, R. V.; KENT, M. Biorrevelações: testes de ancestralidade genética em perspectiva antropológica comparada. In: SANTOS, R. V.; GIBBON, S.; BELTRÃO, J. F. (Org.). Identidades emergentes, genética e saúde: perspectivas antropológicas. Rio de Janeiro: Garamond; Fiocruz, 2012. p. 233-267.

HEATH, D.; RAPP, R.; TAUSSIG, K.-S. Genetic citizenship. In: NUGENT, D.; VINCENT, J. (Org.). A companion to the anthropology of politics. London: Blackwell 2004. p. 152-167.

KENT, M. A importância de ser uro: movimentos indígenas, políticas de identidade e pesquisa genética nos Andes Peruanos. Horizontes Antropológicos, ano 17, n. 35, p. 297-324, 2011.

MARKS, J. Human Genome Diversity Project: Impact on indigenous communities. In: COOPER, D. N. (Org.). Encyclopedia of the human genome. New York: Macmillan, 2003. p. 14.

MOTTA, A. Essencialismo genético: por que a genética do século 21 soa como a biologia do século 19? 2007. Disponível em: <http://www.ibase.br/ modules.php?name=Conteudo\&pid=1812>. Acesso em: 7 dez. 2010. 
PARFITT, T.; EGOROVA, Y. Genetics, history, and identity: the case of the Bene Israel and the Lemba. Culture, Medicine and Psychiatry, v. 29, n. 2, p. 193-224, 2005.

RABINOW, P. Essays on the anthropology of reason. Princeton: Princeton University Press, 1996.

REARDON, J. Race to the finish: identity and governance in an age of genomics. Princeton: Princeton University Press, 2005.

ROSE, N. The politics of life itself: biomedicine, power, and subjectivity in the twenty-first century. Princeton: Princeton University Press, 2006.

SIMPSON, B. Imagined genetic communities: Ethnicity and essentialism in the twenty-first century. Anthropology Today, v. 16, n. 3, p. 3-6, 2000.

SUAREZ-KURTZ, G. Farmacogenômica e a diversidade genética da população brasileira. Cadernos de Saúde Pública, v. 25, n. 8, p. 1650-1651, 2009.

TALLBEAR, K. Narratives of race and indigeneity in the Genographic Project. Journal of Law, Medicine and Ethics, v. 35, n. 3, p. 412-424, 2007. 